$\xi=-$ 国

\title{
Development and Application of the TPACK-P Education Program for Pre-Service Teachers' TPACK
}

\author{
Seong-Won Kim ${ }^{1}$, Youngjun Lee* \\ 1,* Dept. of Computer Education, Korea National University of Education,250 Taeseongtabyeon-ro, Grangnae-myeon, \\ Heungdeok-gu, Cheongju, Chungbuk, 28174, Republic of Korea \\ *Corresponding author E-mail: yjlee@knue.ac.kr
}

\begin{abstract}
Background/Objectives: This study aimed to investigate and complement the ways of improving the Technological Pedagogical Content Knowledge-Programming (TPACK-P) educational program and verify the improved program's effect on pre-service teachers'TPACK.

Methods/Statistical Analysis: The TPACK-P educational program was conducted for 19 pre-service teachers; two difficulty items were investigated. A survey was administered to identify any improvement. To verify the effect of the improved program on the pre-service teachers' TPACK, two programs involving distinct technological tools were applied to the control and experimental groups. To generate comparable results, the same research procedure was adopted as in a previous study, with some modifications.

Findings: The pre-service teachers had difficulties in the process of learning programming, designing lessons, and developing programs in the TPACK-P educational program. In addition, they needed increased time for learning programming and analyzing the activities in the TPACK-P class. Therefore, the improved TPACK-P educational program added programming-based activities (analysis of curriculum based on programming, analysis of TPACK-P instructional cases, and development of the TPACK-P program in the programming environment). As a result of engaging the pre-service teachers in the improved TPACK-P educational program, the preservice teachers' TPACK was effectively developed in all areas. Moreover, it was found to be more effective in improving the knowledge of technology than information and communication technology (ICT)-based TPACK educational program was.

Improvements/Applications: This study can be used as a basic foundation for carrying out programming-based TPACK education for pre-service teachers.
\end{abstract}

Keywords: TPACK, Pre-service teacher, TPACK-P, Programming, Difficulties in programming

\section{Introduction}

In modern times, the shapes of the economy, society, education, and life are changing rapidly, and the development of technology has played a major role in these changes. Technology has been introduced into existing disciplines, creating new disciplines and leading social change [1]. As a result, technology's importance is increasing, and it is predicted that technology will transform the future society into something that has not been experienced previously [2].

As in other areas, the need for technology is emphasized in education. Traditional education has focused on delivering knowledge to students from the perspective of behaviorism theory [3]. However, as education from a constructivist perspective has emerged, the shape of education has also changed. As a result, technology has been actively introduced to overcome difficulties in traditional education and support effective learning in the classroom, from Overhead projector to computers, smartphones, and tablet Personal computer [4]. However, although the tools of technology have actively been developed, the purpose of practically using technology in the classroom has not changed much [5]. This phenomenon has arisen because teachers do not use technology properly in class. In short, teachers have trouble integrating technology into the classroom.
One of the reasons why teachers do not use technology properly in the classroom environment is their lack of knowledge concerning technology [6]. As a result of this, the need for knowledge of technology has been emphasized, and TPACK, which combines technology knowledge with Pedagogical Content Knowledge (PCK), has emerged. TPACK is a way of understanding the functions and limitations of technology and using technology appropriately in accordance with the contents of the curriculum, teaching method, and educational context [7,8]. TPACK's importance has increased with the development of technology, and studies seeking to improve in-service and pre-service teachers' TPACK have been actively conducted [9].

Technology is basically a context-neutral tool. Therefore, although the knowledge of technology has increased, teachers have difficulty using it in schools, where various contextual factors are at work. Thus, research on the available technological tools has been carried out. Furthermore, programming languages, representing is a tool for reducing the influence of the educational context and developing and applying it according to the teachers' needs, has attracted attention [10]. As the effectiveness of the program has been verified when applied to subjects other than computer science [11,12], studies have been conducted to introduce programming language as a technological tool in TPACK [13]. Thus, the TPACK-P education model, a programming-based TPACK education model based on design- 
based learning(DBL), has been developed through the analysis of previous research $[10,14,15]$.

The TPACK-P educational model was created to improve preservice teachers' TPACK [15]. In addition, the TPACK-P educational program was developed from the model. In previous research, the TPACK-P educational program was applied to preservice teachers, and the results showed that it is only effective in some areas of TPACK. TPACK requires integrated development, not individual knowledge development $[16,17,18]$. Therefore, when all the specific areas are developed in pre-service teachers' TPACK, the pre-service teachers' teaching expertise can be improved, while technology integration into the classroom can be achieved [19-22]. Accordingly, in this study, the TPACK-P educational program was applied in pre-service teacher training, and the factors causing difficulties in the pre-service teachers' TPACK development were investigated in the TPACK-P educational program. Furthermore, the TPACK-P educational program was improved based on the factors studied in the research. Moreover, to verify the effect of the improved TPACK-P educational program on the pre-service teachers' TPACK, a study was conducted on applying the education program. This study confirmed the effectiveness of the TPACK-P educational program.

\section{Development of the Improved TPACK-P Educational Program}

\subsection{Method}

\subsubsection{Research Procedure}

In this study, the TPACK-P educational program was developed to improve pre-service teachers' TPACK. To accomplish this, the following procedure was carried out: First, prior TPACK-P research was analyzed, and second, difficulties and improvements were investigated concerning the design process of programming based teaching/learning for pre-service teachers who received the TPACK-P educational program. Following this, the results of the questionnaire were analyzed and improvement methods for the TPACK-P educational program were derived. Finally, based on the improvements, the TPACK-P educational program was improved.

\subsubsection{Participants}

The participants in this study were 19 pre-service teachers attending the Korea National University of Education(KNUE) in Korea. The recruitment of the pre-service teacher opened the TPACK-related course at KNUE, and the pre-service teachers applied for the course. In this study, the research subjects were pre-service teachers who agreed to participate and completed the administered survey.

In terms of their characteristics, there were more female (79\%) than male $(21 \%)$ pre-service teachers. In addition, the pre-service teachers had various majors, including technology, Chinese, geography, home economics, English, and music. In terms of their university level, they were mainly freshmen (58\%), sophomores $(26 \%)$, junior (14\%) and there were no seniors.

Less than half the pre-service teachers had no experience programming $(42 \%)$. The pre-service teachers with programming experience $(42 \%)$ had mostly experienced block-based programming. A small number of pre-service teachers had experienced text-based programming languages. However, the pre-service teachers had not learned much programming in depth; rather, they were exposed to simple examples in lectures and activities. The participants in this study had all attended classes related to Pedagogical Knowledge (PK), but less than half had had lectures related to PCK $(47 \%)$.

\subsubsection{Treatments}

The treatment was conducted during KNUE's Fall/Winter semester in 2016. The researchers offered a lecture on the TPACK-P educational program at KNUE, and the pre-service teachers who participated were aware of the lecture contents in advance. The lectures were conducted from August 29, 2016 to December 9, 2016 (15 weeks), for 3 hours each week. In this study, the TPACK-P educational program developed by Kim and Lee (2017) was used for the treatments [10]. In the 15-week educational program, the pre-service teachers analyzed the problem of the subject, explored the theoretical content of TPACK and programming language environment and example from the TPACK class and curriculum contents, designed and applied a programming-based class, and evaluated the class. The educational programs were designed as DBL, and the pre-service teachers taught the material via a team project $[10,14]$.

\subsubsection{Investigation}

After conducting the team project, the pre-service teachers were asked two questions to investigate the difficulties they experienced and points they would like to see improved in the TPACK-P educational program. The first question related difficulties in the processes of learning programming and creating a program to be used in class. The second question asked how the TPACK-P educational program could be improved. The pre-service teachers described their thoughts, and their responses were categorized. To ensure validity, three experts compared and analyzed the results. In addition, the researchers sought to achieve a consensus on their categorization of the pre-service teachers' opinions.

\subsection{Results}

All the pre-service teachers reported that they had difficulty in the process of learning programming and creating programs that could be used in class. They experienced major difficulties in the TPACK-P educational program concerning the three following topics: learning the programming language, designing programming-based lessons, and creating the designed program.

\subsubsection{Difficulty in Learning a Programming Language}

Seven out of the 19 pre-service teachers $(36.8 \%)$ had difficulty in learning programming. Most were unfamiliar with the programming language(Scratch) that was first presented encountered. Therefore, it was not easy to become accustomed to using scratch. Especially, the participants reported difficulty in creating and utilize variables, and they found it difficult to implement a logical structure. Furthermore, although the preservice teachers found it easy to create scratch programs from the lectures, it was difficult for them to explain and understand how the program works $[24,25]$.

\subsubsection{Difficulty in Designing a Programming-based Class}

Eight pre-service teachers $(42 \%)$ had difficulty in designing programming-based lessons according to the content and curriculum. The participants recognized the educational effects of programming through the TPACK-P educational program. However, they had difficulty in finding ways of introducing programming into their curriculum and utilize programming for instruction in accordance with the curriculum. One of the reasons for this difficulty was a gap between the programs that the preservice teacher anticipated creating before learning programming and the programs that could actually be produced after learning programming. These differences caused difficulties in designing programming-based lessons to fit the subjects' programming competencies. As a result, the pre-service teachers had difficulty in determining what program to produce in the curriculum and what program to introduce in the class. In addition, it was difficult 
to for then to conceive what programs were needed for actual classes and determine what programs could be applied to the curriculum.

\subsubsection{Difficultyin the Process of Designing Programs}

Seven pre-service teachers (36.8\%) answered that they experienced difficulty in the final development process in the programming-based class. The most common reason for this difficulty was that they did not know what blocks to use in the process of developing in scratch. Although the pre-service teachers designed the program they wanted to create, they could not confirm the blocks in the program-making process.

\subsubsection{Improvement of the TPACK-P Educational Program for Pre-Service Teachers}

The pre-service teachers voiced several opinions on the improvement of the TPACK-P educational program. First, more time allocation was needed for programming learning and analyzing the example of programming-based instruction. Some pre-service teachers who participated in this study had experienced programming previously, but there were also preservice teachers who were new to programming. In addition, there were many pre-service teachers who majored in subjects that were less relevant to programming, such as music, home economics, geography, English, ethics, Chinese, early-childhood, and environmental studies. These factors made it difficult to become accustomed to programming. Therefore, the pre-service teachers had many difficulties in becoming familiar with the programming language and producing the designed program. These results are in line with research investigating the difficulties in existing programming education $[24,25]$. Thus, this study showed that preservice teachers had difficulty in developing programs using block-based programming language, and thus, they needed more time to do so.

Second, it was necessary to analyze the class example that was designed by using programming. In the TPACK-P educational program, activities for analyzing the TPACK class practice example were conducted, but there was no activity relating to analyzing the programming-based TPACK class case. Because of the lack of such class activities, the pre-service teachers said that the notion of how programming could be introduced into subject and curriculum was vague.

The responses to the two questions suggest that the pre-service teachers had difficulty in finding ways of using programming in class and learning programming. The TPACK-P educational program uses scratch, a block-based programming language, to enable pre-service teachers to easily learn and use programming in class. In addition, it is expected that, if pre-service teachers understand the programming development environment, it will be easier to generate various teaching materials through remixing about program in Scratch, which is an advantage of scratch. Unlike the expectation of researcher, the pre-service teachers had difficulty learning the programming that was first encountered. Thus, difficulty in the programming learning process is considered an impediment to the development of Technological Knowledge (TK)among pre-service teachers [24-28]. To develop comprehensive TPACK based on the development of pre-service teachers' TK, it is necessary to supplement pre-service teachers' effective learning of programming in the TPACK-P educational program [20-22]. Therefore, it is necessary to develop an educational method for pre-service teachers to gain competencies that will help in producing the necessary programs for programming-based TPACK lessons.

The TPACK-P educational program examines the problems of the subject; the process of designing the programming-based lesson was carried out according to the characteristics of the subject and the curriculum based on these problems. Pre-service teachers reported that they understood the educational effects of programming (Technological Pedagogical Knowledge, TPK), but they complained about the problems that the use of programming in their subject and curriculum (Technological Content Knowledge (TCK) and TPACK). Thus, in accordance with Kim and Lee's (2017) findings, this result showed that the TPACK-P educational program did not support the development of preservice teachers' TCK and TPACK [10]. To solve these problems, it is necessary to make efforts to connect the problems of the subject, curriculum, and programming. One way of solving the difficulties that the pre-service teachers experienced is analyzing TPACK teaching examples based on programming [28]. The preservice teachers had many difficulties in thinking about how to apply unfamiliar programming to the class. Therefore, analyzing the cases of TPACK classes conducted using programming will help pre-service teachers to explore how they can use programming in various subjects, including their specialized subject areas [29].

An analysis of the curriculum based on programming was also carried out. It was found that the pre-service teachers lacked understanding of the curriculum related to their major in the context of programming. Thus, there are many vulnerabilities in the process of linking programming and the curriculum in TPACK classes. As a result, analyzing how pre-service teachers can utilize programming in their subject's curriculum can help link the curriculum and programming. This will also help in designing programming-based lesson for introducing programming in the curriculum [30].

Finally, the pre-service teachers had difficulties in determining how to actually produce the program once it had been designed. In this study, scratch was used as the programming language; this is a block-based language with sharing and remixing capacities. Scratch's remix function allows users to develop programs shared by other users for their goals $[12,13]$. Therefore, if pre-service teachers understand the scratch development environment, and they find and remix programs that meet their purposes, they can reduce the effort of designing and developing programs from the beginning $[23,24]$. To develop these competencies, it is necessary for pre-service teachers to practice TPACK-P-based instructional programs based on specific achievement standards. Practice makes it easier for pre-service teachers to improve their ability to properly use programming in education rather than their programming capacity as program developers. Based on the findings, the TPACK-P educational program was improved as shown in Table 1.

Table 1: Content of improved TPACK-P educational program

\begin{tabular}{|l|l|l|}
\hline Domain & Content & Elements of TPACK-P* \\
\hline Analysis & Analysis of problem in subject & $1,6,9$ \\
\hline \multirow{4}{*}{ Investigation } & Investigation of programming environment (with TPACK programming) & $2,4,5$ \\
\cline { 2 - 3 } & Investigation of TPACK & $4,5,6$ \\
\cline { 2 - 3 } & Investigation of example of TPACK Class & $1,4,6,8$ \\
\cline { 2 - 3 } & Investigation of example of programming TPACK Class & $1,2,4,5,6,8$ \\
\cline { 2 - 3 } & Investigation of curriculum (with programming) & 1,9 \\
\hline Design & Design of class with TPACK-P & $1,2,8$ \\
\hline Application & Microteaching & 3,7 \\
\hline
\end{tabular}


* 1. Brainstorming; 2. Design of class with programming; 3. Instructional criticism; 4. Investigation of TPACK model; 5. Investigation of programming environment; 6. Reflection of class; 7. Microteaching; 8. Collaboration; 9. Investigation of curriculum

\section{Application of the Improved TPACK-P Educational Program}

\subsection{Method}

\subsubsection{Research Procedure}

The purpose of this study was to verify pre-service teachers' acceptance of the improved TPACK-P educational program. For this study, the same research design and procedure were used as in as previous studies [10]. To verify the effectiveness of the educational program, the recruited pre-service teachers were divided into a control and an experimental group (Kim \& Lee, 2017). To verify the TPACK changes of pre-service teachers, testing was carried out before and after applying the TPACK-P educational program. The results of the test tool were statistically analyzed, and the effect of the improved TPACK educational program on the TPACK of the pre-service teachers was examined.

\subsubsection{Participants}

The goal of this study was to validate the improved TPACK-P educational program. The research subjects comprised 44 preservice teachers attending KNUE. For recruitment, the researchers conducted a university lecture at KNUE on the topic of technological tools. The pre-service teachers applied for the classes based on the lecture plan and agreed to participate in the research; those who completed the questionnaire were selected for the experiment. As a result, the study group consisted of 22 preservice teachers in the control group and 20 pre-service teachers in the experimental group as show in Table 2.

In terms of the characteristics of the study subjects, there were differences between the groups, but they were not significant. The control group consisted of more males (55\%) than females (45\%), while the experimental group included more females $(40 \%)$ than males $(60 \%)$. In the control group, the participants were sophomores $(68 \%)$ or juniors $(32 \%)$. The experimental group showed a similar distribution, the participants were sophomores $(35 \%)$ or juniors $(45 \%)$, but freshmen $(10 \%)$ and seniors $(10 \%)$ were also present. The pre-service teachers had diverse majors in both groups.

Considering the pre-service teachers' programming experience, nearly $50 \%$ of the participants in both groups had some experience. However, there was a difference in the types of programming languages they were familiar with. Except for one pre-service teacher, all the experimental group participants had used block-based programming languages; in addition, all but one had used a text-based programming language, and all had taken courses related to PK. About $75 \%$ of the pre-service teachers had taken courses related to PCK.

Table 2: Characteristics of participants in study

\begin{tabular}{|c|c|c|c|c|c|}
\hline \multicolumn{6}{|c|}{ Gender } \\
\hline Group & \multicolumn{2}{|l|}{ Male } & \multicolumn{2}{|l|}{ Female } & Total \\
\hline Con. & \multicolumn{2}{|l|}{$12(55)$} & \multicolumn{2}{|l|}{$10(45)$} & $22(100)$ \\
\hline Exp. & \multicolumn{2}{|l|}{$8(40)$} & \multicolumn{2}{|l|}{$12(60)$} & $20(100)$ \\
\hline \multicolumn{6}{|l|}{ Grade } \\
\hline Group & Freshman & Sophomore & Junior & Senior & Total \\
\hline Con. & $0(0)$ & $15(68)$ & $7(32)$ & $0(0)$ & $22(100)$ \\
\hline Exp. & $2(10)$ & $7(35)$ & $9(45)$ & $2(10)$ & $20(100)$ \\
\hline \multicolumn{6}{|l|}{ Major } \\
\hline Group & \multicolumn{4}{|l|}{ Major } & Total \\
\hline \multirow{6}{*}{ Con. } & Chemistry & $4(18)$ & Earth science & $3(13)$ & \multirow{6}{*}{$22(100)$} \\
\hline & English & $3(13)$ & Environment & $2(9)$ & \\
\hline & Physics & $2(9)$ & Computer & $2(9)$ & \\
\hline & Mathematics & $2(9)$ & Technology & $1(5)$ & \\
\hline & Early-childhood & $1(5)$ & Social science & 1(5) & \\
\hline & History & $1(5)$ & & & \\
\hline \multirow{5}{*}{ Exp. } & Chemistry & $4(20)$ & Biology & $4(20)$ & \multirow{5}{*}{$20(100)$} \\
\hline & Computer & $3(15)$ & Fine art & $3(15)$ & \\
\hline & Chinese & $2(10)$ & Ethics & $1(5)$ & \\
\hline & English & $1(5)$ & Germany & $1(5)$ & \\
\hline & Geography & $1(5)$ & & & \\
\hline \multicolumn{6}{|c|}{ Experience of Programming } \\
\hline Group & \multicolumn{2}{|l|}{ Yes } & \multicolumn{2}{|l|}{ No } & Total \\
\hline Con. & \multicolumn{2}{|l|}{$10(45)$} & \multicolumn{2}{|l|}{$12(55)$} & $22(100)$ \\
\hline Exp. & \multicolumn{2}{|l|}{$11(55)$} & \multicolumn{2}{|l|}{$9(45)$} & $20(100)$ \\
\hline \multicolumn{6}{|c|}{ Experience of pedagogy lecture } \\
\hline Group & \multicolumn{2}{|l|}{ Yes } & \multicolumn{2}{|l|}{ No } & Total \\
\hline Con. & \multicolumn{2}{|l|}{$22(100)$} & \multicolumn{2}{|l|}{$0(0)$} & $22(100)$ \\
\hline Exp. & \multicolumn{2}{|l|}{$20(100)$} & \multicolumn{2}{|l|}{$0(0)$} & $20(100)$ \\
\hline
\end{tabular}




\begin{tabular}{|l|l|l|l|}
\hline \multicolumn{2}{|l|}{ Experience of pedagogical content lecture } & No & Total \\
\hline Group & Yes & $6(27)$ & $22(100)$ \\
\hline Con. & $16(73)$ & $5(25)$ & $20(100)$ \\
\hline Exp. & $15(75)$ & & \\
\hline
\end{tabular}

${ }^{*}$ Con.: Control group, Exp.: Experimental group

\subsubsection{Treatments}

This study aimed to observe the TPACK change of pre-service teachers in the improved TPACK-P educational program, which was developed as shown in Table. This program was used for preservice teacher training in the experimental group. To compare the results with those of the previous study, the control group completed the TPACK educational program based on information and communication technology (ICT). The content of the control group's education program was the same as that in the previous study [10]. The treatment of the education program was conducted as part of a liberal arts lecture at KNUE in Korea. The treatment was conducted during the Spring/Summer semester of 2017, from March 2to June 14. The pre-service teachers were trained for 15 weeks, and the program duration was 3 hours each week.

\subsubsection{Test Tools}

The tests employed the same TPACK measurement tool as in the previous study [10]. In that study, the TPACK test tool developed by Park and Kang (2014) was employed [31]. The research tool developed by Chai et al. (2013) as a test tool for pre-service teachers' TPACK has been used in many studies [32], but the test had to be verified for Korea's cultural background [33]. Therefore, Park and Kang (2014) localized 42 questions, and verified the validity and reliability of the items by conducting an expert review and exploratory factor analysis [31]. Through this, a TPACK test tool composed of has seven sections and 36 items.

\subsubsection{Analysis}

This study also compared the pre- and post-test results of the two groups using an independent sample $t$-test. Through this comparison, the difference between groups on the pre- and posttests was confirmed. In addition, the paired-sample $t$-test was conducted for the two groups, and the pre-service teachers' TPACK changes resulting from the TPACK educational program with different technological tools were observed.

\subsection{Results}

\subsubsection{TPACK Comparison of Pre-Service Teachers on the Pre- Test}

First, the TPACK difference between the experimental and control groups was analyzed in the pre-test. In the independent-sample $t$ test results, there was no statistically significant differences between the experimental group (mean $[\mathrm{M}]=3.001$, standard deviation $[\mathrm{SD}]=.668)$ and control group $(\mathrm{M}=3.063, \mathrm{SD}=.432)$, $\mathrm{p}=.722$. In addition, there was no statistically significant difference between PK $(t=.495, p=.623)$, TK $(t=-.088, p=.930)$, Content Knowledge (CK) $(t=1.433, p=.160)$, PCK $(t=1.706, p=$ $.096)$, TCK $(t=.821, p=.417)$, TPK $(t=-.586, p=.561)$, or TPACK $(t=-.811, p=.422)$ in the sub-areas. These results show that pre-service teachers' TPACK results on the pre-test were equal between the experimental and control groups. The detailed comparison of the groups' pre-test results is shown in Table 3.

Table 3: The result of pre-service teachers' TPACK in pre-test

\begin{tabular}{|c|c|c|c|c|c|c|c|}
\hline & & Group & $N$ & $M$ & $S D$ & $t$ & $p$ \\
\hline \multirow{14}{*}{ Sub-Domain } & \multirow{2}{*}{ PK } & con. & 22 & 3.403 & .403 & \multirow{2}{*}{.495} & \multirow{2}{*}{.623} \\
\hline & & exp. & 20 & 3.329 & .560 & & \\
\hline & \multirow{2}{*}{ TK } & con. & 22 & 2.886 & .851 & \multirow{2}{*}{-.088} & \multirow{2}{*}{.930} \\
\hline & & exp. & 20 & 2.913 & 1.062 & & \\
\hline & \multirow{2}{*}{ CK } & con. & 22 & 3.273 & .672 & \multirow{2}{*}{1.433} & \multirow{2}{*}{.160} \\
\hline & & exp. & 20 & 2.963 & .731 & & \\
\hline & \multirow{2}{*}{ PCK } & con. & 22 & 3.205 & .593 & \multirow{2}{*}{1.706} & \multirow{2}{*}{.096} \\
\hline & & exp. & 20 & 2.842 & .781 & & \\
\hline & \multirow{2}{*}{ TCK } & con. & 22 & 2.939 & .760 & \multirow{2}{*}{.821} & \multirow{2}{*}{.417} \\
\hline & & exp. & 20 & 2.717 & .993 & & \\
\hline & \multirow{2}{*}{ TPK } & con. & 22 & 2.856 & .806 & \multirow{2}{*}{-.586} & \multirow{2}{*}{.561} \\
\hline & & exp. & 20 & 3.008 & .878 & & \\
\hline & \multirow{2}{*}{ TPACK } & con. & 22 & 2.773 & .840 & \multirow{2}{*}{-.811} & \multirow{2}{*}{.422} \\
\hline & & exp. & 20 & 3.000 & .976 & & \\
\hline \multirow{2}{*}{\multicolumn{2}{|c|}{ Total }} & con. & 22 & 3.063 & .432 & \multirow{2}{*}{.359} & \multirow{2}{*}{.722} \\
\hline & & exp. & 20 & 3.001 & .668 & & \\
\hline
\end{tabular}

\subsubsection{TPACK Changes on the Pre- and Post-Tests for the Control Group}

Pre-service teachers who received the ICT-based TPACK educational program showed improved TPACK results on the post-test $(\mathrm{M}=3.001, \mathrm{SD}=.668)$ compared with the pre-test $(\mathrm{M}=$ 3.001, $\mathrm{SD}=.668)$. However, these differences were not statistically significant, $t=-1.519, p=.144$. There were differences in each domain; while PK $(t=-2.098, p=.048)$ and
TPACK $(t=-2.280, \mathrm{p}=.003)$ showed statistically significant changes between pre-test and post-test, there were no statistically significant differences in $\operatorname{TK}(t=-.290, p=.774), \operatorname{CK}(t=-.925$, $p=.365), \operatorname{PCK}(t=.000, p=1.000), \operatorname{TCK}(t=-.319, p=.753)$, or $\operatorname{TPK}(t=-.777, p=.446)$. These results showed that the ICT-based TPACK educational program affects only some of the TPACK sub-areas. The $t$-test results for the control group are shown in Table 4. 
Table 4: Change of TPACK of pre-service teachers in control group

\begin{tabular}{|c|c|c|c|c|c|c|c|}
\hline & & test & $N$ & $M$ & $S D$ & $t$ & $p$ \\
\hline \multirow{12}{*}{ Sub-Domain } & \multirow{2}{*}{ PK } & Pre & \multirow{2}{*}{22} & 3.403 & .403 & \multirow{2}{*}{-2.098} & \multirow{2}{*}{$.048^{*}$} \\
\hline & & Post & & 3.636 & .478 & & \\
\hline & TK & Post & 22 & 2.932 & 1.044 & -.290 & .774 \\
\hline & \multirow{2}{*}{ CK } & Pre & \multirow{2}{*}{22} & 3.273 & .672 & \multirow{2}{*}{-.925} & \multirow{2}{*}{.365} \\
\hline & & Post & & 3.443 & .824 & & \\
\hline & \multirow{2}{*}{ PCK } & Pre & \multirow{2}{*}{22} & 3.205 & .593 & \multirow{2}{*}{.001} & \multirow{2}{*}{1.000} \\
\hline & & Post & & 3.205 & .765 & & \\
\hline & \multirow{2}{*}{ TCK } & Pre & \multirow{2}{*}{22} & 2.939 & .760 & \multirow{2}{*}{-.319} & \multirow{2}{*}{.753} \\
\hline & & Post & & 2.985 & .923 & & \\
\hline & \multirow{2}{*}{ TPK } & Pre & \multirow{2}{*}{22} & 2.856 & .806 & \multirow{2}{*}{-.777} & \multirow{2}{*}{.446} \\
\hline & & Post & & 3.038 & .883 & & \\
\hline & TPACK & Post & 22 & 3.189 & .849 & -2.280 & $.033^{*}$ \\
\hline \multirow{2}{*}{\multicolumn{2}{|c|}{ Total }} & Pre & \multirow{2}{*}{22} & 3.063 & .432 & \multirow{2}{*}{-1.519} & \multirow{2}{*}{.144} \\
\hline & & Post & & 3.236 & .625 & & \\
\hline
\end{tabular}

\subsubsection{TPACK Changes on the Pre- and Post-Tests for the} Experimental Group

In the experimental group, the pre-service teachers showed improved TPACK results on the post-test $(M=3.561, S D=.385)$ compared with the pre-test $(M=3.001, S D=.668)$. In addition, these changes exhibited statistically significant differences, $t=-$ $5.642, p<.001$. Looking at the changes between the sub-areas, statistically significant improvements were seen in all the subareas, namely $\mathrm{PK}(t=-2.613, p=.017)$, TK $(t=-4.814, p<.001)$, $\mathrm{CK}(t=-4.568, p<.001), \operatorname{PCK}(t=-4.077, p=.001), \mathrm{TCK}(t=-$ $5.659, p<.001)$, TPK $(t=-3.577, p=.002)$, and TPACK $(t=-$ $3.272, p=.004)$. The results showed that the improved TPACK-P educational program influenced the pre-service teachers' TPACK improvement. The results of the paired sample $t$-test are shown in Table 5.

Table 5: Change of TPACK of pre-service teachers in experimental group

\begin{tabular}{|c|c|c|c|c|c|c|c|}
\hline & & test & $N$ & $M$ & $S D$ & $t$ & $p$ \\
\hline \multirow{14}{*}{ Sub-Domain } & \multirow{2}{*}{ PK } & Pre & \multirow{2}{*}{20} & 3.329 & .560 & \multirow{2}{*}{-2.613} & \multirow{2}{*}{$.017^{* *}$} \\
\hline & & Post & & 3.650 & .471 & & \\
\hline & \multirow{2}{*}{ TK } & Pre & \multirow{2}{*}{20} & 2.913 & 1.062 & \multirow{2}{*}{-4.814} & \multirow{2}{*}{$.000^{* *}$} \\
\hline & & Post & & 3.500 & .683 & & \\
\hline & \multirow{2}{*}{ CK } & Pre & \multirow{2}{*}{20} & 2.963 & .731 & \multirow{2}{*}{-4.568} & \multirow{2}{*}{$.000^{* *}$} \\
\hline & & Post & & 3.550 & .536 & & \\
\hline & \multirow{2}{*}{ PCK } & Pre & \multirow{2}{*}{20} & 2.842 & .781 & \multirow{2}{*}{-4.077} & \multirow{2}{*}{$.001^{* *}$} \\
\hline & & Post & & 3.333 & .554 & & \\
\hline & \multirow{2}{*}{ TCK } & Pre & \multirow{2}{*}{20} & 2.717 & .993 & \multirow{2}{*}{-5.659} & \multirow{2}{*}{$.000^{* *}$} \\
\hline & & Post & & 3.633 & .518 & & \\
\hline & \multirow{2}{*}{ TPK } & Pre & \multirow{2}{*}{20} & 3.008 & .878 & \multirow{2}{*}{-3.577} & \multirow{2}{*}{$.002^{* *}$} \\
\hline & & Post & & 3.608 & .517 & & \\
\hline & \multirow{2}{*}{ TPACK } & Pre & \multirow{2}{*}{20} & 3.000 & .976 & \multirow{2}{*}{-3.272} & \multirow{2}{*}{$.004^{* *}$} \\
\hline & & Post & & 3.650 & .540 & & \\
\hline \multirow{2}{*}{\multicolumn{2}{|c|}{ Total }} & Pre & \multirow{2}{*}{20} & 3.001 & .668 & \multirow{2}{*}{-5.642} & \multirow{2}{*}{$.000^{* *}$} \\
\hline & & Post & & 3.561 & .385 & & \\
\hline
\end{tabular}

$\mathrm{p}<.05,{ }^{* *} \mathrm{p}<.01$

\subsubsection{TPACK Comparison of Pre-Service Teachers on the} Post-Test

The pre-service teachers' TPACK results on the post-test showed a statistically significant difference in the control and experimental groups, $t=-5.642, p<.001$. In addition, the TPACK value of the experimental group $(\mathrm{M}=3.561, \mathrm{SD}=.385)$ was larger than that of the control group $(\mathrm{M}=3.236, \mathrm{SD}=.625)$. These results showed that the improved TPACK-P educational program is more effective for the TPACK development of pre-service teachers than the ICT-based TPACK educational program is. The difference between the groups in the sub-areas showed a statistically significant difference in TK $(t=-2.063, p=.046)$, TCK $(t=-2.770$, $p=.008)$, TPK $(t=-2.521, p=.016)$, and TPACK $(t=-2.074, p=$ $.045)$. Furthermore, these areas showed larger values in the experimental group than they did in the control group. Therefore, the development of technology-related knowledge exhibited that the TPACK-P educational program was more effective than the ICT-based TPACK educational program was. In contrast, there was no significant difference between the two groups for PK $(t=-$ 093, $p=.926)$, CK $(t=-.493, p=.625)$, and PCK $(t=-.620, p=$ $.539)$. 
Table 6: The result of pre-service teachers' TPACK in post-test

\begin{tabular}{|c|c|c|c|c|c|c|c|}
\hline & & Group & $N$ & $M$ & $S D$ & $t$ & $p$ \\
\hline \multirow{12}{*}{ Sub-Domain } & \multirow{2}{*}{ PK } & con. & 22 & 3.636 & .478 & \multirow{2}{*}{-.093} & \multirow{2}{*}{.926} \\
\hline & & exp. & 20 & 3.650 & .471 & & \\
\hline & \multirow{2}{*}{ TK } & con. & 22 & 2.932 & 1.044 & \multirow{2}{*}{-2.063} & \multirow{2}{*}{$.046^{*}$} \\
\hline & & exp. & 20 & 3.500 & .683 & & \\
\hline & CK & con. & 22 & 3.443 & .824 & -.493 & .625 \\
\hline & \multirow{2}{*}{ PCK } & con. & 22 & 3.205 & .765 & \multirow{2}{*}{-.620} & \multirow{2}{*}{.539} \\
\hline & & exp. & 20 & 3.333 & .554 & & \\
\hline & \multirow{2}{*}{ TCK } & con. & 22 & 2.985 & .923 & \multirow{2}{*}{-2.770} & \multirow{2}{*}{$.008^{* *}$} \\
\hline & & exp. & 20 & 3.633 & .518 & & \\
\hline & \multirow{2}{*}{ TPK } & con. & 22 & 3.038 & .883 & \multirow{2}{*}{-2.521} & \multirow{2}{*}{$.016^{*}$} \\
\hline & & exp. & 20 & 3.608 & .517 & & \\
\hline & TPACK & exp. & 20 & 3.650 & .540 & -2.074 & $.045^{*}$ \\
\hline \multirow{2}{*}{\multicolumn{2}{|c|}{ Total }} & con. & 22 & 3.236 & .625 & \multirow{2}{*}{-2.048} & \multirow{2}{*}{$.048^{*}$} \\
\hline & & exp. & 20 & 3.561 & .385 & & \\
\hline
\end{tabular}

\subsection{Discussion}

In this study, the improved TPACK-P educational program was applied in pre-service teacher training, and its effects were verified. Previous studies on the TPACK-P educational program have shown an effect on pre-service teachers' TPACK. However, the program was only found to affect TPK and TPACK in the specific sub-areas. In this study, the TPACK-P educational program was added to the analysis of a curriculum based on programming, analysis of programming-based instructional examples, and practice on development processes in the TPACK$\mathrm{P}$ program. The results showed that TK and TCK exhibited no statistically significant differences in the experimental group. However, the change was more effective than it was in the ICTbased TPACK educational program.

Although improvements were not seen in every area of the preservice teachers' TPACK, it could be confirmed that all the technology-related knowledge improved as programming-related activities were added. Paik (2017) verified the TPACK model and confirmed that TCK and TPK affect the development of TPACK. In addition, TK was found to be strongly related to TCK and TPK [34-38]. Therefore, this result illustrated that technology-related knowledge is essential for the development of pre-service teachers' TPACK. This study found that the improved TPACK-P educational program has a greater effect on the factors that affect TPACK development than the existing TPACK-P programs do. Therefore, it can be confirmed that programming activities have a great influence on the development of pre-service teachers' TPACK. In addition, the development of knowledge related to technology can affect the teaching expertise development of preservice teachers through TPACK development [39].

In this study, an ICT-based TPACK educational program was introduced to the control group. In previous studies, ICT-based TPACK educational programs were found to be effective for preservice teachers' TPACK development $[14,40]$. However, in this study, unlike in previous research, there was little effect on the TPACK change of pre-service teachers [10]. Thus, the same educational program was introduced, but the TPACK change of the pre-service teachers was different [41]. Therefore, there are factors that influence the development of TPACK in pre-service teachers, and it is necessary to examine specific factors for developing pre-service teachers' TPACK [34, -38]. In this study, the results showed that the effectiveness of the TPACK educational program depends on the technological tools employed in the program.
Goos et al. (2010) found that, while the need for technology in education has long been emphasized, it takes a lot of effort to convince teachers to take up the technology in their classes. Thus, the integration of technology and education represents a challenge [19], as pre-service teachers' integration of technology into the classroom occurs in a stepwise fashion, but it can be difficult to take the steps [42]. Technology can only be integrated into the classroom if it is developed from the stage of simply recognizing it to the stages of accepting, adjusting, exploring, and confirming the technology in the classroom context. Due to structural difficulties and the educational situation, the pre-service teachers can have difficulties integrating technology into education $[43,44]$. When the programming language was introduced as a tool for the TPACK educational program of the pre-service teachers, they could integrate the programming language into the class more easily than they could the other technology tools. Moreover, the programming languages were effective in reducing pre-service teachers' structural difficulties related to integrating technology into their classes.

To develop pre-service teachers' TPACK, knowledge of all areas should be integrated and developed [44]. This requires the development of TPACKs through an integrated approach rather than individual knowledge approaches [45]. Therefore, the education program needs to develop all areas of pre-service teachers' TPACK [21]. However, the improved TPACK-P educational program was not effective in doing this; specifically, it did not effect the development of PK, CK, or PCK. Paik (2017) stated that PK and CK affect TCK and TPK when knowledge, expectations, and self-efficacy related to technology are high [34]. Therefore, it is necessary to develop PK, CK, and PCK, as well as technology-related knowledge, to improve pre-service teachers' TPACK [43]. However, PK, CK, and PCK are difficult to develop through educational programs because they involve many factors, such as subject majors and characteristics. In addition, they vary greatly depending on the pre-service teacher's level. Therefore, it is necessary to examine the effect of the TPACK-P educational program on the pre-service teachers' $\mathrm{PK}, \mathrm{CK}$, and PCK under the influence of several controlled factors, as well as to examine the improvement direction of the TPACK-P educational program for development of PK, CK, and PCK $[36,46]$.

\section{Conclusion}

In this study, the TPACK-P educational program was improved, and a study was conducted to verify the results. Several conclusions can be drawn from the study. 
First, the pre-service teachers had difficulties in programmingrelated activities in the existing TPACK-P educational program. They had issues with the programming language learning process, designing programming-based lessons, and designing TPACK-P programs. In addition, the pre-service teachers said that it is necessary to analyze the time for learning programming and analyzing programming-based instruction to design a class based on it.

Second, a TPACK-P educational program was developed that improved programming-based activities. From the initial difficulties and improvements in the TPACK-P educational program, it was confirmed that programming-based activities are needed. Therefore, programming-based activities (analysis of the curriculum based on programming, analysis of example of TPACK-P lessons, and development of TPACK-P programs in a programming environment) were added to the TPACK-P educational program.

Third, the improved TPACK-P educational program was effective for the pre-service teachers' TPACK development. Compared with the ICT-based TPACK educational program, the TPACK-P educational program proved to be effective in the development of TK, TCK, TPK, and TPACK of pre-service teachers. Unlike the existing TPACK-P educational program, it was confirmed that the TK and TCK of pre-service teachers could be developed. However, the PK, CK and PCK of pre-service teachers did not differ according to the technological tools used in the TPACK educational program.

In this study, the same testing tools were used as in the previous research to compare the effectiveness with the existing TPACK-P educational program. Programming languages are not contextneutral tools, but they are less influenced by the educational context. Therefore, they are different from the existing technological tools. As a result, there may be a difference in the significance of programming and technology in the existing TPACK test. Therefore, in a subsequent study, as programming was introduced as a technological component, the nature of the technology should be reviewed with the aim of determining how to complement the TPACK testing tools accordingly. In addition, a programming-based TPACK test tool should be developed and verified.

The goal of the TPACK-P educational program is the development of pre-service teaching expertise. In addition to knowledge, various factors, such as educational beliefs, attitudes toward technology, techno-stress, and efficacy influence preservice teaching expertise. This study focused on TPACK, which is knowledge related to technology. To develop pre-service teachers' teaching expertise, it is necessary to study how the TPACK-P educational program affects various factors. Through these studies, the direction of improvement of the TPACK-P educational program can be derived for the development of preservice teachers' teaching expertise.

\section{Acknowledgment}

This work was supported by the National Research Foundation of Korea(NRF) grant funded by the Korea government(MSIP) (No. 2016R1A2B4010522)

\section{References}

[1] Becker, S. A., Cummins, M., Davis, A., Freeman, A., Hall, C. G., \& Ananthanarayanan, V. (2017). NMC horizon report: 2017 higher education edition (pp. 1-60). The New Media Consortium.

[2] Schwab, K. (2017). The fourth industrial revolution. Crown Business.

[3] Martin, S., Diaz, G., Sancristobal, E., Gil, R., Castro, M., \& Peire, J. (2011). New technology trends in education: Seven years of forecasts and convergence. Computers \& Education, 57(3), 18931906.

[4] Glenn, M., \&D'Agostino, D. (2008). The future of higher education:
How technology will shape learning. New Media Consortium.

[5] Sanders, M. (2001). New paradigm or old wine? The status of technology education practice in the United States.

[6] Mishra, P., \& Koehler, M. J. (2006). Technological pedagogical content knowledge: A 6 framework for teacher knowledge. Teachers college record, 108(6), 1017.

[7] Koehler, M., \& Mishra, P. (2009). What is technological pedagogical content knowledge (TPACK)?. Contemporary issues in technology and teacher education, 9(1), 60-70.

[8] Shulman, L. S. (1986). Those who understand: Knowledge growth in teaching. Educational researcher, 15(2), 4-14

[9] Koehler, M. J., Shin, T. S., \& Mishra, P. (2012). How do we measure TPACK? Let me count the ways. In Educational technology, teacher knowledge, and classroom impact: A research handbook on frameworks and approaches (pp. 16-31). IGI Global.

[10] KIM, S. W., \& LEE, Y. (2017). Development of TPACK-P Education Program for Improving Technological Pedagogical Content Knowledge of Pre-service Teachers. Journal of The Korea Society of Computer and Information, 22(7), 1

[11] 11. Choi, E.S., Lee, Y., \& Paik, S.H. (2017). The Effects of Programming-Based Lessons on Science Teachers` Perceptions Related to TPACK. Journal of the Korean Association for Science Education, 37(4), 693-703.

[12] Noh, H, \& Paik, S.H. (2015). Students` Perception of Scratch Program using High School Science Class. Journal of the Korean Association for Science Education, 35(1), 53-64.

[13] Choi, J. W., Lee, E.K., \& Lee, Y. (2015). Extension of Technology in TPACK: Tools, Application Software, and Programming. Proceeding of The Korea Society of Computer and Information, 23(2), 137-138.

[14] Baran, E., \& Uygun, E. (2016). Putting technological, pedagogical, and content knowledge (TPACK) in action: An integrated TPACKdesign-based learning (DBL) approach. Australasian Journal of Educational Technology, 32(2).

[15] KIM, S. W., \& LEE, Y. (2017). Development of Educational Model for Technological Pedagogical Content Knowledge based on Programming. Proceeding of The Korea Society of Computer and Information, 25(1), 261-262.

[16] Lee, E., Kim, S. W., \& Lee, Y. (2017, October). An Investigation of the Relationship between Self-Efficacy and Technological Pedagogical Content Knowledge (TPACK) among Pre-service Teachers. In E-Learn: World Conference on E-Learning in Corporate, Government, Healthcare, and Higher Education (pp. 627-631). Association for the Advancement of Computing in Education (AACE).

[17] KIM, S. W., \& LEE, Y. (2017). DEVELOPMENT AND APPLICATION OF ARDUINO-BASED EDUCATION PROGRAM FOR HIGH SCHOOL STUDENTS'. Journal of Theoretical \& Applied Information Technology, 95(18).

[18] KIM, S. W., \& LEE, Y. (2017). A STUDY OF EDUCATIONAL METHOD USING APP INVENTOR FOR ELEMENTARY COMPUTING EDUCATION. Journal of Theoretical \& Applied Information Technology, 95(18).

[19] Goos, M. (2010). A sociocultural framework for understanding technology integration in secondary school mathematics. PNA, 5(1), 1-10.

[20] Chang, K. (2017). Pre-Service Secondary Mathematics Teacher Education Program for Technology Integrated Curriculum: The Present and Tasks. The journal of educational research in mathematics, 27(1), 137-156.

[21] Doering, A., Veletsianos, G., Scharber, C., \& Miller, C. (2009). Using the technological, pedagogical, and content knowledge framework to design online learning environments and professional development. Journal of Educational Computing Research, 41(3), 319-346.

[22] Ryu, K., \& Lee, Y. (2017). Effects of Online Teacher Learning Community Activities linked with Internship Course for the Improvement of Elementary Pre-service Teacher's TPACK. The Journal of Korean Teacher Education, 34(2), 417-437.

[23] Choi, J., \& Lee, Y. (2014). The analysis of Learners` difficulties in programming Learning. The Journal of Korean association of computer education, 17(5), 89-98.

[24] Sung, J., Kim, S., \& Kim H. (2015). Analysis of Art and Humanity Major Learners` Features in Programming Class. The Journal of Korean association of computer education, 18(3), 25-35.

[25] Renumol, V., Jayaprakash, S., \& Janakiram, D. (2009). Classification of cognitive difficulties of students to learn computer programming. Indian Institute of Technology, India.

[26] Carter, J., Dewan, P., \& Pichiliani, M. (2015, February). Towards 
incremental separation of surmountable and insurmountable programming difficulties. In Proceedings of the 46th ACM Technical Symposium on Computer Science Education (pp. 241246).ACM.

[27] Milne, I., \& Rowe, G. (2002). Difficulties in learning and teaching programming-views of students and tutors. Education and Information technologies, 7(1), 55-66.

[28] Koh, J. H., \& Divaharan, H. (2011). Developing pre-service teachers' technology integration expertise through the TPACKdeveloping instructional model. Journal of Educational Computing Research, 44(1), 35-58.

[29] Chai, C. S., Koh, J. H. L., Tsai, C. C., \& Tan, L. L. W. (2011) Modeling primary school pre-service teachers' Technological Pedagogical Content Knowledge (TPACK) for meaningful learning with information and communication technology (ICT). Computers \& Education, 57(1), 1184-1193.

[30] Tondeur, J., van Braak, J., Sang, G., Voogt, J., Fisser, P., \& Ottenbreit-Leftwich, A. (2012). Preparing pre-service teachers to integrate technology in education: A synthesis of qualitative evidence. Computers \& Education, 59(1), 134-144.

[31] Park, K. C., \& Kang, S. J. (2014). The Development of Cognitive Path Model on Technological Pedagogical Content Knowledge(TPACK) among Elementary·Secondary Teachers. Korean Journal of Teacher Education, 30(4), 349-375.

[32] Chai, C. S., Ng, E. M., Li, W., Hong, H. Y., \&Koh, J. H. (2013) Validating and modelling technological pedagogical content knowledge framework among Asian pre-service teachers. Australasian Journal of Educational Technology, 29(1).

[33] Helms, J. E. (1992). Why is there no study of cultural equivalence in standardized cognitive ability testing?. American Psychologist, 47(9), 1083.

[34] Paik, J. (2017). Validation of Technology, Pedagogy, and Conten Knowledge (TPACK) Model with Data Collected from Inclusive School. Proceeding of The Korean Society of Special Education, 13-22.

[35] Chai, C. S., Koh, J. H. L., Ho, J. H. N., \& Tsai, C. C. (2012) Examining pre-service teachers' perceived knowledge of TPACK and cyberwellness through structural equation modeling. Australasian Journal of Educational Technology.

[36] Archambault, L. M., \& Barnett, J. H. (2010). Revisiting technological pedagogical content knowledge: Exploring the TPACK framework. Computers \& Education, 55(4), 1656-1662.

[37] Abbitt, J. T. (2011). Measuring technological pedagogical content knowledge in pre-service teacher education: A review of current methods and instruments. Journal of Research on Technology in Education, 43(4), 281-300.

[38] Akman, Ö., \& Güven, C. (2015). TPACK Survey Developmen Study for Social Sciences Teachers and Teacher Candidates. International Journal of Research in Education and Science, 1(1), 110 .

[39] Lee, D. H., \& Whang, W. H. (2018). A study on TPACK of mathematics teachers: Focusing on recognitions and educational needs of TPACK. THE MATHEMATICAL EDUCATION, 57(1), $1-36$.

[40] Kim, D. (2017). TPACK as a Research Tool for Technology Integration into Classroom: A Review of Research Trends in Korea. The Journal of Elementary Education, 30(4), 1-22.

[41] Niess, M. L. (2011). Investigating TPACK: Knowledge growth in teaching with technology. Journal of educational computing research, 44(3), 299-317.

[42] Niess, M. L., Ronau, R. N., Shafer, K. G., Driskell, S. O., Harper, S. R., Johnston, C., Browning, C., AsliÖzgün-Koca, S. \&Kersaint, G. (2009). Mathematics teacher TPACK standards and development model. Contemporary Issues in Technology and Teacher Education, 9(1), 4-24.

[43] Bong, M., \& Song, G.G. (2004). Korean Middle School Teachers and Students' Perceptions and Attitudes Toward ICT Use in Mathematics Classroom. Journal of Research in Curriculum Instruction, 8, 147-165.

[44] Kim, S. (2012). Improving Mathematics Pre-service Teachers' Assessment Competence through Practice and Reflection. The journal of educational research in mathematics, 22(2), 277-292.

[45] Shin, W. S., Han, I.S., \& Eom, M.R. (2012). Influence of Technology Integration Course on Pre-service Teachers' Technological Pedagogical and Content Knowledge (TPACK) Journal of the Korean Association of information Education, 16(1), 71-80.

[46] Chai, C. S., Koh, J. H. L., \& Tsai, C. C. (2010). Facilitating preservice teachers' development of technological, pedagogical, and content knowledge (TPACK). Educational Technology \& Society, 13(4), 63-73 